\title{
Nonisothermal melt-crystallization kinetics for three linear aromatic polyesters
}

\author{
Pitt Supaphol*, Nujalee Dangseeyun, Phornphon Srimoaon, Manit Nithitanakul \\ The Petroleum and Petrochemical College, Chulalongkorn University, Soi Chula 12, \\ Phyathai Road, Pathumwan, Bangkok 10330, Thailand
}

Received 3 January 2003; received in revised form 23 April 2003; accepted 24 April 2003

\begin{abstract}
The kinetics of nonisothermal crystallization of three different types of linear aromatic polyester, namely poly(ethylene terephthalate) (PET), poly(trimethylene terephthalate) (PTT), and poly(butylene terephthalate) (PBT), which are different in their number of methylene groups (i.e. 2, 3, and 4 for PET, PTT, and PBT, respectively), was investigated using differential scanning calorimetry (DSC). Analysis of the data was carried out based on the Avrami, Tobin, Ozawa, and Ziabicki models. It was found that the Avrami model provided a more satisfactorily good fit to the experimental data for these polyesters than did the Tobin model. The Ozawa model was found to describe the experimental data fairly well. The Ziabicki's kinetic crystallizability parameter $G$ for these polyesters was found to be of the following order: PBT > PTT > PET. The effective energy barrier for nonisothermal crystallization process of these polyesters, determined by the Friedman method, was found to be an increase function with the relative degree of crystallinity.
\end{abstract}

(c) 2003 Elsevier Science B.V. All rights reserved.

Keywords: Poly(ethylene terephthalate); Poly(trimethylene terephthalate); Poly(butylene terephthalate); Nonisothermal crystallization kinetics

\section{Introduction}

Poly(trimethylene terephthalate) (PTT), a relatively new linear aromatic polyester, is a member of the polyester family, with three methylene units in its chemical structure. The synthesis of PTT was first reported in 1941 [1], but it was not commercially available then due to the high production cost of one of the reactants, 1,3-propanediol. Since then, PTT has become commercially available and is produced by Shell Chemicals under the trade name Corterra $^{\mathrm{TM}}$.

Studies related to the kinetics of polymer crystallization are of great importance in polymer processing,

\footnotetext{
* Corresponding author. Fax: +66-2215-4459. E-mail address: pitt.s@chula.ac.th (P. Supaphol).
}

due to the fact that the resulting physical properties are strongly dependent on the morphology formed and the extent of crystallization occurring during processing. It is therefore very important to understand the processing-structure-property interrelationships of the studied materials, which, in this case, are PET, PTT, and PBT.

The very first report on the nonisothermal crystallization of PET was carried out in 1971 when Ozawa [2] proposed a new method to analyze data for the solidification of semicrystalline polymers cooled at a constant cooling rate. The cooling rates used in that report were 1,2 , and $4{ }^{\circ} \mathrm{C} \mathrm{min}-1$. The Avrami exponents, estimated by using the Ozawa approach, were reported to be ca. 3.4, 3.6, and 3.6 at 220, 222, and $235^{\circ} \mathrm{C}$, respectively, which were found to be comparable to the results reported earlier [3-6]. 
We now report the nonisothermal crystallization kinetics for PTT as compared to those for PET and PBT determined using differential scanning calorimetry (DSC). The experimental data were analyzed based on the Avrami, Tobin, Ozawa, and Ziabicki macrokinetic models. The effective energy barrier for nonisothermal crystallization process for these polyesters was estimated based on the differential isoconversional method of Friedman.

\section{Theoretical background}

The most common approach used to describe the overall isothermal crystallization kinetics is the Avrami model [7-9], in which the relative crystallinity as a function of time $\theta(t)$ can be expressed in the following form:

$\theta(t)=1-\exp \left[-\left(K_{\mathrm{A}} t\right)^{n_{\mathrm{A}}}\right] \in[0,1]$,

where $K_{\mathrm{A}}$ and $n_{\mathrm{A}}$ are the Avrami crystallization rate constant and the Avrami exponent, respectively. Usually, the Avrami rate constant $K_{\mathrm{A}}$ is written in the form of the composite Avrami rate constant $k_{\mathrm{A}}$ (i.e. $k_{\mathrm{A}}=$ $\left.K_{\mathrm{A}}^{\mathrm{n}}\right) \cdot k_{\mathrm{A}}$ (the dimension of which is given in (time) ${ }^{-n}$ ) is not only a function of temperature, but also a function of the Avrami exponent $n_{\mathrm{A}}$. As a result, use of $K_{\mathrm{A}}$ should be more preferable than use of $k_{\mathrm{A}}$ due partly to the facts that it is independent of the Avrami exponent $n_{\mathrm{A}}$ and its dimension is given in (time) $)^{-1}$. It should be noted that both $K_{\mathrm{A}}$ and $n_{\mathrm{A}}$ are constants specific to a given crystalline morphology and type of nucleation for a particular crystallization condition [10] and that, based on the original assumptions of the theory, the value of the Avrami exponent $n_{\mathrm{A}}$ should be an integer ranging from 1 to 4 .

In the study of nonisothermal crystallization using DSC, the energy released during the crystallization process appears to be a function of temperature rather than time as in the case of isothermal crystallization. As a result, the relative crystallinity as a function of temperature $\theta(T)$ can be formulated as

$\theta(T)=\frac{\int_{T_{\mathrm{o}}}^{T}\left(\mathrm{~d} H_{\mathrm{c}} / \mathrm{d} T\right) \mathrm{d} T}{\Delta H_{\mathrm{c}}}$,

where $T_{\mathrm{o}}$ and $T$ represent the onset and an arbitrary temperature, respectively, $\mathrm{d} H_{\mathrm{c}}$ is the enthalpy of crystallization released during an infinitesimal temperature range $\mathrm{d} T$, and $\Delta H_{\mathrm{c}}$ is the overall enthalpy of crystallization for a specific cooling condition.

To use Eq. (1) for the analysis of nonisothermal crystallization data obtained by DSC, it must be assumed that the sample experiences the same thermal history as designated by the DSC furnace. This may be realized only when the thermal lag between the sample and the furnace is kept minimal. If this assumption is valid, the relation between the crystallization time $t$ and the sample temperature $T$ can be formulated as

$t=\frac{T_{\mathrm{o}}-T}{\phi}$,

where $\phi$ is the cooling rate. According to Eq. (3), the horizontal temperature axis observed in a DSC thermogram for the nonisothermal crystallization data can readily be transformed into the time scale.

The important consideration for the Avrami approach is that the model is appropriate only for the early stages of crystallization. Complications arise due to the effects of growth site impingement and secondary crystallization process, which were disregarded for the sake of simplicity in the original derivation of the model. A theory of phase transformation kinetics with growth site impingement was proposed by Tobin [11-13]. According to this approach, the equation of phase transition in the form of the relative crystallinity as a function of time $\theta(t)$ reads

$\theta(t)=\frac{\left(K_{\mathrm{T}} t\right)^{n_{\mathrm{T}}}}{1+\left(K_{\mathrm{T}} t\right)^{n_{\mathrm{T}}}} \in[0,1]$,

where $K_{\mathrm{T}}$ is the Tobin rate constant, and $n_{\mathrm{T}}$ the Tobin exponent. Based on this proposition, the Tobin exponent need not be an integral [11-13], and it is mainly governed by different types of nucleation and growth mechanisms. It should be noted that, according to the original applications [14-16], the Tobin rate constant is written in the form of the composite Tobin rate constant $k_{\mathrm{T}}$ (i.e. $k_{\mathrm{T}}=K_{\mathrm{T}}^{\mathrm{n}}$ ), which is not only a function of time, but also a function of the Tobin exponent $n_{\mathrm{T}}$ (similar to the case of $k_{\mathrm{A}}$ mentioned previously). As a result, use of $K_{\mathrm{T}}$ should be more preferable than use of $k_{\mathrm{T}}$ due partly to the facts that it is independent of the Tobin exponent $n_{\mathrm{T}}$ and its dimension is given in

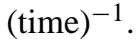

Based on the mathematical derivation of Evans [14], Ozawa [2] extended the Avrami theory [7-9] to be able to describe the nonisothermal crystallization data 
without the use of $x$-scale transformation. Mathematically, the relative crystallinity function $\theta(T)$ can be represented as a function of cooling rate as

$1-\frac{\chi_{\mathrm{T}}}{\chi_{\infty}}=1-\theta(T)=\exp \left(-\frac{k_{\mathrm{O}}}{\phi^{n_{\mathrm{O}}}}\right)$,

where $\chi_{\mathrm{T}}$ is the absolute crystallinity developed at an arbitrary temperature $T, \chi_{\infty}$ is the ultimate absolute crystallinity, $k_{\mathrm{O}}$ is the Ozawa crystallization rate function, and $n_{\mathrm{O}}$ is the Ozawa exponent. It should be noted that the Ozawa kinetic parameters (i.e. $k_{\mathrm{O}}$ and $n_{\mathrm{O}}$ ) hold similar physical meaning as those of the Avrami ones. Analytically, the Ozawa kinetic parameters (i.e. $k_{\mathrm{O}}$ and $n_{\mathrm{O}}$ ) can be extracted by drawing a least-squared line to the double-logarithmic plot of $\ln [-\ln (1-\theta(T))]$ versus $\ln (\phi)$ for a fixed temperature, where $k_{\mathrm{O}}$ is taken as the antilogarithmic value of the $y$-intercept and $n_{\mathrm{O}}$ is simply the negative value of the slope.

Instead of describing the crystallization process with complicated mathematic models, Ziabicki [15-17] proposed that the kinetics of polymeric phase transformation can be described by a first-order kinetic equation of the form

$\frac{\mathrm{d} \theta(t)}{\mathrm{d} t}=K(T)[1-\theta(t)]$,

where $\theta(t)$ is the relative crystallization as a function of time and $K(T)$ is a temperature-dependent crystallization rate function. In the case of nonisothermal crystallization, functions $K(T)$ and $\theta(t)$ vary and are dependent on the cooling rate used.

For a given cooling condition, Ziabicki [15-17] showed that the crystallization rate function $K(T)$ can be described by a Gaussian function of the following form:

$K(T)=K_{\max } \exp \left[-4 \ln 2 \frac{\left(T_{\mathrm{c}}-T_{\max }\right)^{2}}{D^{2}}\right]$,

where $T_{\max }$ is the temperature at which the crystallization rate is maximum, $K_{\max }$ is the crystallization rate at $T_{\max }$, and $D$ is the half-width of the crystallization rate-temperature function. With use of the isokinetic approximation, integration of Eq. (7) over the whole crystallizable range of temperatures $\left(T_{\mathrm{g}}<T<T_{\max }^{0}\right)$, for a given cooling condition, leads to an important characteristic value for the crystallization ability $G$ of a semicrystalline polymer, which is defined as

$G=\int_{T_{\mathrm{g}}}^{T_{\max }^{0}} K(T) \mathrm{d} T \approx 1.064 K_{\max } D$.

According to the approximate theory [15], the kinetic crystallizability $G$ characterizes the degree of crystallinity obtained when the polymer is cooled at unit cooling rate from the melting temperature to the glass transition temperature [17].

In case of nonisothermal crystallization studies using DSC where cooling rate is a variable, Eq. (8) can be applied when the crystallization rate function $K(T)$ is replaced with a derivation function of the relative crystallinity $\dot{\theta}_{\phi}(T)$ specific for each cooling rate studied (i.e. crystallization rate function at different cooling rates). Therefore, Eq. (8) is replaced by

$G_{\phi}=\int_{T_{\mathrm{g}}}^{T_{\max }^{0}} \dot{\theta}_{\phi}(T) \mathrm{d} T \approx 1.064 \dot{\theta}_{\max , \phi} D_{\phi}$,

where $\dot{\theta}_{\max , \phi}$ and $D_{\phi}$ are the maximum crystallization rate and the half-width of the derivative relative crystallinity as a function of temperature $\dot{\theta}_{\phi}(T)$. According to Eq. (9), $G_{\phi}$ is the kinetic crystallizability at an arbitrary cooling rate $\phi$. The kinetic crystallizability at unit cooling rate $G$ can therefore be obtained by normalizing $G_{\phi}$ with $\phi$ (i.e. $G=G_{\phi} / \phi$ ). It should be noted that this procedure was first realized by Jeziorny [18].

While offering a simple way of evaluating corresponding kinetic parameters specific to each model, the Avrami, Tobin, and Ozawa analyses do not suggest a means for evaluating the effective energy barrier for nonisothermal crystallization process $\Delta E$. In light of this, various mathematical procedures [19-21] were proposed for evaluating the $\Delta E$ value. The main objective of these methods is to define a finite relationship between the peak temperature $T_{\mathrm{p}}$ obtained for a given condensed phase reaction and the heating rate $\phi$ used. A major concern for use of these procedures in obtaining the kinetic information for the nonisothermal crystallization process which occurs on cooling has recently been raised [22], since the original mathematic expression for these procedures does not permit substitution of the negative heating rates, $\phi$ (i.e. cooling rates). However, this problem has largely been 
avoided by dropping off the minus sign in the negative heating rates [23].

For a process that occurs on cooling, such as nonisothermal crystallization of polymer melts, reliable values of the effective energy barrier can be obtained, for example, by the differential isoconversional method of Friedman [24] or by the integral isoconversional method of Vyazovkin [25,26]. In this work, the Friedman method will be used, due mainly to the reliability and simplicity of the method $[22,26]$. The Friedman equation is expressed as

$\ln \left(\dot{\theta}_{\theta}(t)\right)=A-\frac{\Delta E_{\theta}}{R T}$,

where $\dot{\theta}_{\theta}(t)$ is the instantaneous crystallization rate, as a function of time at a given conversion $\theta, A$ is an arbitrary preexponential parameter, and $\Delta E_{\theta}$ is the effective energy barrier of the process at a given conversion $\theta$. By plotting the instantaneous crystallization rate data measured from nonisothermal experiments conducted at various cooling rates against the corresponding inversed temperature for a given conversion, the effective energy barrier for a nonisothermal crystallization process can be determined.

\section{Experimental}

\subsection{Materials}

Poly(trimethylene terephthalate) (PTT) was supplied in pellet form by Shell Chemicals (USA) (Corterra CP509201). The weight- and number-average molecular weights of this resin were determined to be ca. 78,100 and 34,700 Da, respectively. Poly(ethylene terephthalate) (PET) was supplied in pellet form by Indo PET (Thailand) (N1). The weight- and number-average molecular weights of this resin were determined to be ca. 84,500 and 41,200 Da, respectively. Poly(butylene terephthalate) (PBT) was supplied in pellet form by LG Chem (Korea) (LUPOX GP-2000). The weight- and number-average molecular weights of this resin were determined to be ca. 71,500 and 36,300 Da, respectively. Molecular weight characterization of these resins was carried out by size-exclusion chromatography (SEC).

\subsection{Sample preparation}

PET, PTT, and PBT resins were dried in a vacuum oven at $140^{\circ} \mathrm{C}$ for $5 \mathrm{~h}$ prior to further use. Films of approximately $200 \mu \mathrm{m}$ thickness were melt-pressed at $280^{\circ} \mathrm{C}$ for PET and $260^{\circ} \mathrm{C}$ for PTT and PBT in a Wabash $\mathrm{V} 50 \mathrm{H}$ compression molding machine under an applied pressure of $4.62 \times 10^{2} \mathrm{MN} \mathrm{m}^{-2}$. After $5 \mathrm{~min}$ holding time, the films were taken out and allowed to cool down to room temperature, under the ambient condition, between the two metal platens. This treatment assured that any previous thermomechanical history was essentially erased, and provided a standard crystalline memory condition for the as-prepared film.

\subsection{Differential scanning calorimetry measurements}

A DSC (DSC-7, Perkin-Elmer) was used to record nonisothermal crystallization exotherms and subsequent melting endotherms of these polyester resins. Calibration for the temperature scale was carried out using a pure indium standard $\left(T_{\max }^{0}=156.6^{\circ} \mathrm{C}\right.$ and $\Delta H_{\mathrm{f}}^{0}=28.5 \mathrm{~J} \mathrm{~g}^{-1}$ ) on every other run to ensure accuracy and reliability of the data obtained. To minimize thermal lag between the polymer sample and the DSC furnace, each sample holder was loaded with a disc-shaped sample weighing around $8.0 \pm 0.5 \mathrm{mg}$ which was cut from the as-prepared films. It is worth noting that each sample was used only once and all the runs were carried out under a nitrogen atmosphere to prevent extensive thermal degradation.

The experiment started with heating each sample from $40{ }^{\circ} \mathrm{C}$ at a heating rate of $80^{\circ} \mathrm{C} \mathrm{min}^{-1}$ to a desired fusion temperature $T_{\mathrm{f}}$ (i.e. at $300^{\circ} \mathrm{C}$ for PET and $280^{\circ} \mathrm{C}$ for PTT and PBT). To ensure complete melting, the sample was kept at the respective $T_{\mathrm{f}}$ for a holding period of $5 \mathrm{~min}$. After this period, each sample was cooled at a desired cooling rate $\phi$, ranging from 5 to $50{ }^{\circ} \mathrm{C} \mathrm{min}^{-1}$, to $30^{\circ} \mathrm{C}$. The sample was then subjected to heating to observe the subsequent melting behavior (recorded using a heating rate of $10^{\circ} \mathrm{C} \mathrm{min}^{-1}$ ). Both the nonisothermal crystallization exotherms and subsequent melting endotherms were recorded for further analysis. The nonisothermal crystallization exotherms were analyzed according to the models aforementioned. 


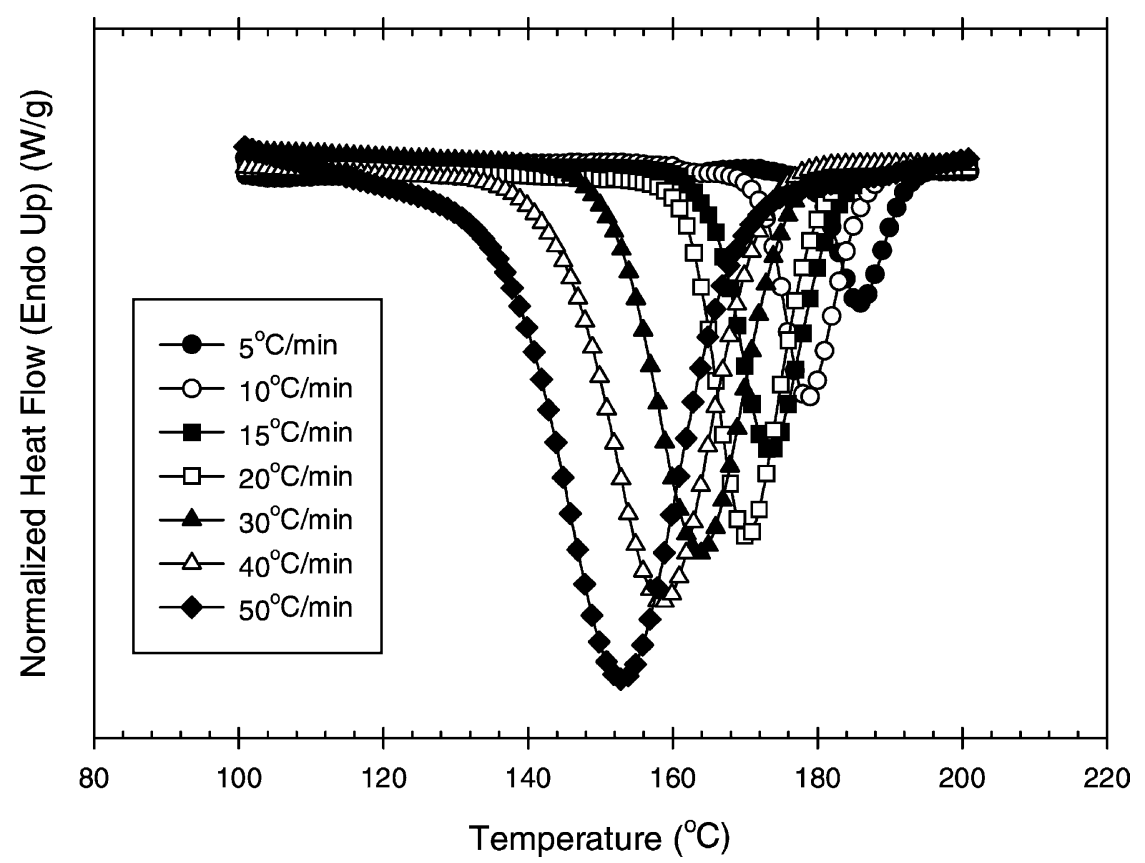

Fig. 1. Nonisothermal melt-crystallization exotherms for PTT recorded at seven different cooling rates.

\section{Results and discussion}

\subsection{Nonisothermal crystallization and subsequent melting behavior}

The crystallization exotherms for PTT for nonisothermal crystallization from the melt at seven different cooling rates ranging from 5 to $50^{\circ} \mathrm{C} \mathrm{min}^{-1}$ are presented in Fig. 1. It is obvious that, when the cooling rate increased, the exothermic trace became wider and shifted to lower temperatures. The ob- servation is generally true for all of the polyesters studied. Table 1 summarizes the characteristic data for nonisothermal crystallization of all the polyesters studied. For each polyester resin, it is evident that the temperature at $1 \%$ relative crystallinity $T_{0.01}$, the temperature at the maximum crystallization rate (i.e. the peak temperature) $T_{\mathrm{p}}$, and the temperature at $99 \%$ relative crystallinity $T_{0.99}$ were all shifted to lower temperatures with increasing cooling rate. It should be noted that the values of $T_{0.01}$ and $T_{0.99}$ will be hereafter used to represent the beginning and the ending

Table 1

Characteristic data from nonisothermal crystallization exotherms for PET, PTT, and PBT

\begin{tabular}{|c|c|c|c|c|c|c|c|c|c|}
\hline \multirow[t]{2}{*}{$\phi\left({ }^{\circ} \mathrm{C} \min ^{-1}\right)$} & \multicolumn{3}{|l|}{ PET } & \multicolumn{3}{|l|}{ PTT } & \multicolumn{3}{|l|}{ PBT } \\
\hline & $T_{0.01}\left({ }^{\circ} \mathrm{C}\right)$ & $T_{\mathrm{p}}\left({ }^{\circ} \mathrm{C}\right)$ & $T_{0.99}\left({ }^{\circ} \mathrm{C}\right)$ & $T_{0.01}\left({ }^{\circ} \mathrm{C}\right)$ & $T_{\mathrm{p}}\left({ }^{\circ} \mathrm{C}\right)$ & $T_{0.99}\left({ }^{\circ} \mathrm{C}\right)$ & $T_{0.01}\left({ }^{\circ} \mathrm{C}\right)$ & $T_{\mathrm{p}}\left({ }^{\circ} \mathrm{C}\right)$ & $T_{0.99}\left({ }^{\circ} \mathrm{C}\right)$ \\
\hline 5 & 216.9 & 196.2 & 182.3 & 192.7 & 185.8 & 179.2 & 206.7 & 196.9 & 189.2 \\
\hline 10 & 206.4 & 185.8 & 169.5 & 188.2 & 178.6 & 170.7 & 204.5 & 192.1 & 184.8 \\
\hline 15 & 203.4 & 179.5 & 161.8 & 184.2 & 173.5 & 163.0 & 201.8 & 187.2 & 177.6 \\
\hline 20 & 200.2 & 171.9 & 134.2 & 181.6 & 170.3 & 160.2 & 198.6 & 186.9 & 172.9 \\
\hline 30 & 195.6 & 167.4 & 121.7 & 177.6 & 163.9 & 148.4 & 196.6 & 181.4 & 169.1 \\
\hline 40 & 195.2 & 163.2 & 107.3 & 173.9 & 158.5 & 139.1 & 193.6 & 176.5 & 164.3 \\
\hline 50 & 192.2 & 163.2 & 107.3 & 169.7 & 153.2 & 130.4 & 191.5 & 174.0 & 159.1 \\
\hline
\end{tabular}




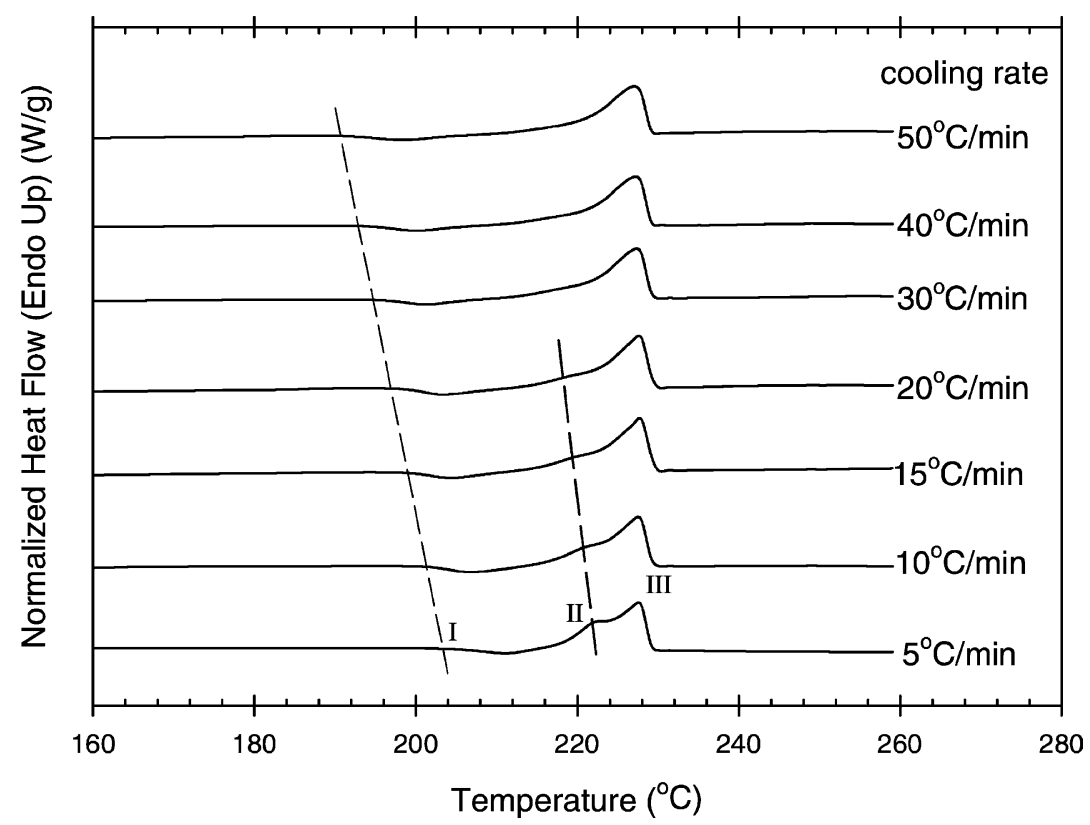

Fig. 2. Subsequent melting endotherms for PTT (recorded at a heating rate of $10^{\circ} \mathrm{Cmin}^{-1}$ ) after nonisothermal crystallization in DSC at seven different cooling rates.

of the crystallization process. The fact that $T_{0.01}, T_{\mathrm{p}}$, and $T_{0.99}$ all decreased with increasing cooling rate suggests that the higher was the cooling rate, the later the crystallization process began and ended (based on the temperature domain).

Fig. 2 shows subsequent melting endotherms $\left(10^{\circ} \mathrm{C} \mathrm{min}{ }^{-1}\right)$ for PTT samples recorded after nonisothermal crystallization at different cooling rates. For subsequent melting endotherms after nonisothermal crystallization at $5{ }^{\circ} \mathrm{C} \mathrm{min}^{-1}$, triple melting endotherms were apparently observed. These peaks were also observed in PTT samples isothermally crystallized at temperatures below $194^{\circ} \mathrm{C}$, and they were labeled as peaks I, II, and III for low-, middle-, and high-temperature melting endotherms, respectively [27]. The occurrence of peak I was postulated to be a result of the melting of the primary crystallites, peak II was a result of the melting of recrystallized crystallites, and peak III was a result of the melting of the recrystallized crystallites of different stabilities [27].

Let us carefully consider Fig. 2. It is obvious that the triple melting behavior was observed for PTT samples which were cooled at cooling rates lower than ca. $20^{\circ} \mathrm{C} \mathrm{min}^{-1}$, while those which were cooled at cool- ing rates greater than ca. $20^{\circ} \mathrm{Cmin}^{-1}$ exhibited double melting behavior (with only peaks I and III being present). Qualitatively, it is evident that the positions of peaks I and II were all found to decrease with increasing cooling rate, while that of peak III did not seem to be affected by changes in the cooling rate. It is also apparent that changes in the cooling rate affected the position of peak I more than they did the position of peak II. The results presented here suggest that the primary crystallites obtained at these cooling rates were not stable, as evidenced by the broad melting endotherm (i.e. peak I) exhibited. Upon further heating, the melted primary crystallites recrystallized to form the crystalline fractions which might have resulted in the occurrence of peaks II and III (for cooling rates lower than ca. $20^{\circ} \mathrm{C} \mathrm{min}-1$ ), or in the occurrence of peak III (for cooling rates greater than $\left.20^{\circ} \mathrm{C} \mathrm{min}^{-1}\right)$.

\subsection{Nonisothermal crystallization kinetics}

In order to obtain relevant kinetic information, the raw data such as those shown in Fig. 1 need to be presented as either the relative crystallinity function 


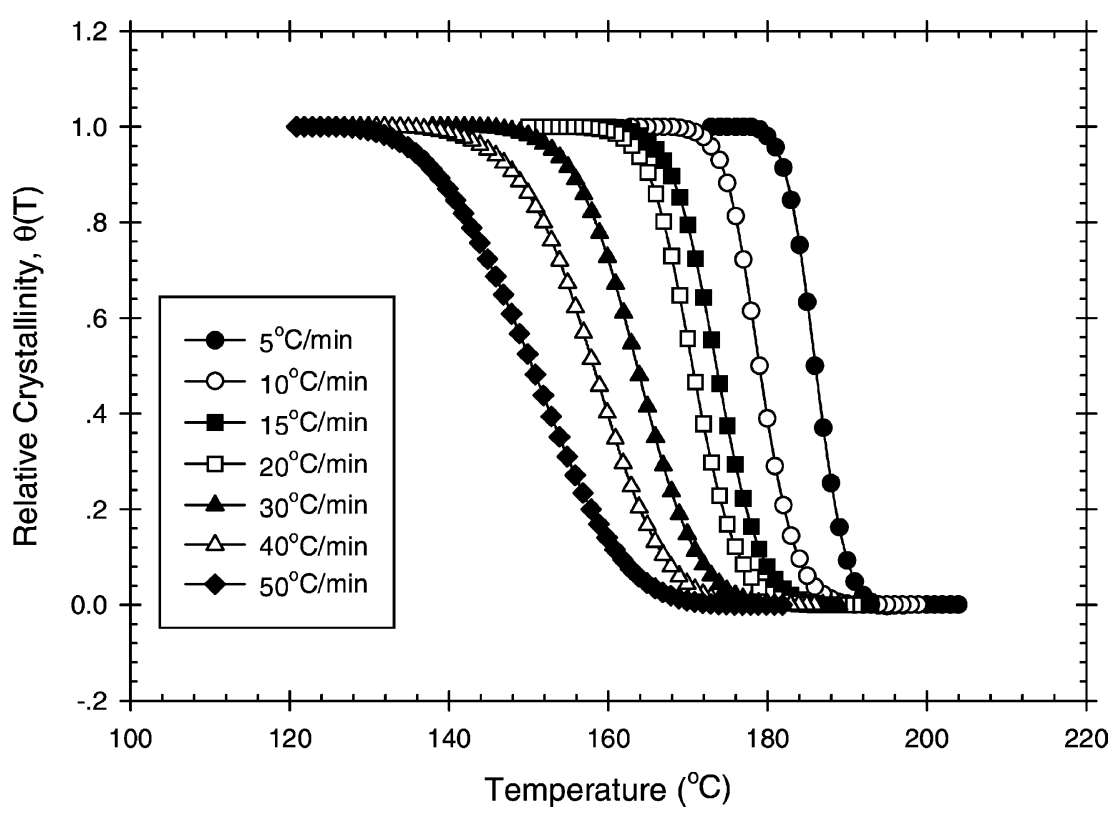

Fig. 3. Relative crystallization as a function of temperature for PTT at seven different cooling rates.

of temperature or of time, depending on the macrokinetic models used to analyze the data. The conversion from the raw data into the relative crystallinity function of temperature can be carried out using Eq. (3). Once the relative crystallinity function of temperature is obtained, conversion into the relative crystallinity function of time can be carried out by transforming the temperature scale into the time scale according to Eq. (4). Figs. 3 and 4 illustrate the relative crystallinity function of temperature $\theta(T)$ and the relative crystallinity function of time $\theta(t)$ for PTT samples nonisothermally crystallized at seven different cooling rates. An important parameter which can be directly taken from the relative crystallinity function of time $\theta(t)$ is the half-time of crystallization, $t_{0.5}$, which is the change in time from the onset of crystallization to the time at $50 \%$ completion. According to Fig. 4 , it is obvious that the $t_{0.5}$ value decreased with increasing cooling rate, suggesting that PTT crystallized faster when the cooling rate was increased. Table 2 summarizes the $t_{0.5}$ values obtained for all of the polyesters studied. For any given cooling rate, the $t_{0.5}$ values of these polyesters were found in the following (descending) order: PET, PTT, and PBT, indicating that PET was the slowest to crystallize, followed by PTT and PBT, respectively.

Table 2

Nonisothermal crystallization kinetic parameters for PET, PTT, and PBT based on Avrami analysis

\begin{tabular}{|c|c|c|c|c|c|c|c|c|c|c|c|c|}
\hline \multirow[t]{2}{*}{$\phi\left({ }^{\circ} \mathrm{C} \min ^{-1}\right)$} & \multicolumn{4}{|l|}{ PET } & \multicolumn{4}{|l|}{ PTT } & \multicolumn{4}{|l|}{ PBT } \\
\hline & $n_{\mathrm{A}}$ & $K_{\mathrm{A}}\left(\min ^{-1}\right)$ & $r^{2}$ & $t_{0.5}(\mathrm{~min})$ & $n_{\mathrm{A}}$ & $K_{\mathrm{A}}\left(\min ^{-1}\right)$ & $r^{2}$ & $t_{0.5}(\mathrm{~min})$ & $n_{\mathrm{A}}$ & $K_{\mathrm{A}}\left(\min ^{-1}\right)$ & $r^{2}$ & $t_{0.5}(\mathrm{~min})$ \\
\hline 5 & 3.98 & 0.18 & 0.9997 & 5.04 & 3.78 & 0.42 & 0.9997 & 2.93 & 3.98 & 0.37 & 0.9997 & 2.50 \\
\hline 10 & 2.97 & 0.37 & 0.9994 & 2.39 & 4.05 & 0.64 & 0.9991 & 1.81 & 6.17 & 0.45 & 1.0000 & 2.09 \\
\hline 15 & 3.29 & 0.43 & 0.9998 & 2.10 & 3.92 & 0.86 & 0.9999 & 1.35 & 4.56 & 0.73 & 0.9998 & 1.27 \\
\hline 20 & 2.26 & 0.43 & 1.0000 & 1.80 & 3.86 & 1.17 & 0.9999 & 0.98 & 3.97 & 1.03 & 0.9983 & 0.89 \\
\hline 30 & 2.56 & 0.65 & 1.0000 & 1.33 & 3.62 & 1.35 & 0.9998 & 0.90 & 4.71 & 1.18 & 0.9999 & 0.79 \\
\hline 40 & 2.54 & 0.75 & 0.9996 & 1.14 & 3.20 & 1.26 & 1.0000 & 0.83 & 3.73 & 1.73 & 0.9998 & 0.53 \\
\hline 50 & 2.86 & 0.88 & 0.9992 & 0.99 & 3.73 & 1.68 & 0.9998 & 0.61 & 3.62 & 2.11 & 0.9998 & 0.43 \\
\hline
\end{tabular}




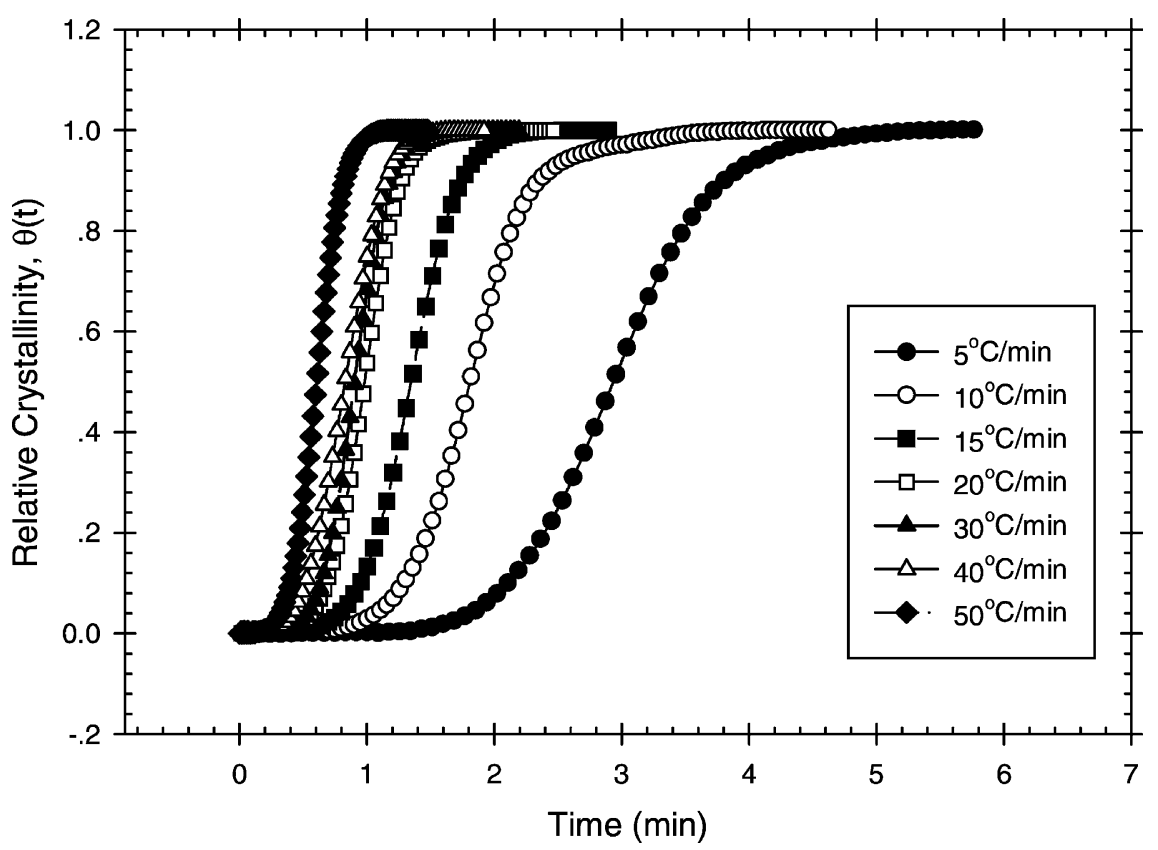

Fig. 4. Relative crystallization as a function of time for PTT at seven different cooling rates.

\subsubsection{Avrami analysis}

As previously mentioned, the analysis was carried out by directly fitting the experimental relative crystallinity function of time $\theta(t)$ data, such as those shown in Fig. 4, to Eq. (1), using a nonlinear multivariable regression program. Only the relative crystallinity data in the range of $10-80 \%$ were used in the fitting. Values of the Avrami kinetic parameters (i.e. $K_{\mathrm{A}}$ and $n_{\mathrm{A}}$ ), including the $r^{2}$ parameter, for all of the polyesters studied are summarized in Table 2.

For PET, the Avrami exponent $n_{\mathrm{A}}$ was in the range of ca. 2.3-4.0, which is in good agreement with that reported by other researchers $[18,28]$. In the case of PTT and PBT, the Avrami exponent $n_{\mathrm{A}}$ was found to range from ca. 3.2 to 4.1 for PTT and from ca. 3.6 to 6.2 for PBT, respectively. Wang et al. [29] reported the Avrami exponent $n_{\mathrm{A}}$ to be in the range of 3.3-4.0 for PTT samples (the number-average molecular weight $=23,000 \mathrm{Da}$ ) nonisothermally crystallized at various cooling rates ranging from 0.63 to $20^{\circ} \mathrm{C} \mathrm{min}^{-1}$, which is comparable to what we have observed in this study.

In addition to the half-time of crystallization, the rate of nonisothermal crystallization can also be de- scribed by values of the Avrami crystallization rate constant $K_{\mathrm{A}}$. For each polyester, the results clearly showed that the Avrami rate constant $K_{\mathrm{A}}$ was an increase function with the cooling rate, suggesting that these polyesters crystallized faster when the cooling rate increased. Comparatively, among these polyesters, PET was clearly the slowest to crystallize at any given cooling rate. PTT, however, was found to crystallize a little faster than PBT when the cooling rates were lower than ca. $30^{\circ} \mathrm{C} \mathrm{min}^{-1}$, which was found to crystallize much slower when the cooling rates were greater than ca. $30^{\circ} \mathrm{C} \mathrm{min}^{-1}$. This finding is in contradiction to the observation based on the half-time of crystallization data in which PTT was found to crystallize slower than PBT at any given cooling rate. The slight discrepancy may lie in the selection of the baseline in order to convert the raw crystallization exotherm data into the relative crystallinity as a function of temperature (or time).

\subsubsection{Tobin analysis}

Similar to the case of the Avrami analysis, the Tobin analysis can be carried out by using either a manual 
Table 3

Nonisothermal crystallization kinetic parameters for PET, PTT, and PBT based on Tobin analysis

\begin{tabular}{|c|c|c|c|c|c|c|c|c|c|}
\hline \multirow[t]{2}{*}{$\phi\left({ }^{\circ} \mathrm{Cmin}^{-1}\right)$} & \multicolumn{3}{|l|}{ PET } & \multicolumn{3}{|l|}{ PTT } & \multicolumn{3}{|l|}{ PBT } \\
\hline & $n_{\mathrm{T}}$ & $K_{\mathrm{T}}\left(\min ^{-1}\right)$ & $r^{2}$ & $n_{\mathrm{T}}$ & $K_{\mathrm{T}}\left(\min ^{-1}\right)$ & $r^{2}$ & $n_{\mathrm{T}}$ & $K_{\mathrm{T}}\left(\min ^{-1}\right)$ & $r^{2}$ \\
\hline 5 & 6.22 & 0.20 & 0.9956 & 5.85 & 0.472 & 0.9987 & 6.40 & 0.41 & 0.9963 \\
\hline 10 & 4.52 & 0.43 & 0.9929 & 5.97 & 0.716 & 0.9993 & 9.16 & 0.48 & 0.9978 \\
\hline 15 & 4.96 & 0.49 & 0.9950 & 6.11 & 0.962 & 0.9984 & 7.23 & 0.81 & 0.9965 \\
\hline 20 & 4.25 & 0.57 & 0.9961 & 6.24 & 1.31 & 0.9982 & 6.13 & 1.15 & 0.9945 \\
\hline 30 & 4.06 & 0.77 & 0.9962 & 5.73 & 1.53 & 0.9986 & 7.35 & 1.30 & 0.9974 \\
\hline 40 & 3.95 & 0.89 & 0.9979 & 6.44 & 1.49 & 0.9879 & 5.92 & 1.95 & 0.9964 \\
\hline 50 & 4.41 & 1.03 & 0.9988 & 5.79 & 1.89 & 0.9986 & 5.81 & 2.38 & 0.9968 \\
\hline
\end{tabular}

or a direct fitting procedure. In this case, the relative crystallinity function of time, $\theta(t)$, such as those shown in Fig. 4, was fitted to Eq. (4) using the direct fitting procedure. Only the relative crystallinity data in the range of $10-80 \%$ were used in the fitting. Values of the Tobin kinetic parameters (i.e. $K_{\mathrm{T}}$ and $n_{\mathrm{T}}$ ), including the $r^{2}$ parameter, for all of the polyesters studied are summarized in Table 3. For all of the three polyesters studied, the Tobin exponent $n_{\mathrm{T}}$ was found to range from ca. 4.0 to 9.2. More specifically, it ranged from ca. 4.0 to 6.2 for PET, from ca. 5.7 to 6.4 for PTT, and from ca. 5.8 to 9.2 for PBT, respectively. With regards to the Tobin crystallization rate constant $K_{\mathrm{T}}$, a dependence similar to that of the Avrami crystallization rate constant $K_{\mathrm{A}}$ was found.

\subsubsection{Comparison between results obtained from Avrami and Tobin analyses}

For PTT and PBT, a direct comparison of the data presented in Tables 2 and 3 suggests that, at low cooling rates (i.e. from 5 to ca. $15^{\circ} \mathrm{C} \mathrm{min}^{-1}$ ), both the Avrami and the Tobin crystallization rate constants were comparable, but, as the cooling rate increased, the Avrami crystallization rate constant became much smaller than the Tobin one. In the case of PET however, the Avrami crystallization rate constant was found to be consistently larger than the Tobin one at low cooling rates (i.e. from 5 to ca. $20^{\circ} \mathrm{C} \mathrm{min}^{-1}$ ) and, with further increase in the cooling rate (i.e. from ca. 30 to $50{ }^{\circ} \mathrm{C} \mathrm{min}^{-1}$ ), the Avrami crystallization rate constant became smaller than the Tobin one. Moreover, it is obvious that, for a given cooling rate, the Avrami exponent obtained for a given polyester was always lower in value than that of the Tobin one. The difference between values of the Tobin expo- nent from the Avrami one is approximately 2.0 on average.

In order to test the efficiency of both models for describing the nonisothermal crystallization kinetics of these polyesters, the best way is to reconstruct the relative crystallinity function of time $\theta(t)$ from the results shown in Tables 2 and 3 according to Eqs. (1) and (4) for the Avrami and the Tobin models, respectively. The reconstructed $\theta(t)$ curves for PET, PTT, and PBT are shown in Fig. 5a-c, respectively. In these figures, the experimental data are shown as different geometrical points, while the predicted curves according to the Avrami and the Tobin models are shown as solid and dotted lines, respectively. Qualitatively, it is obvious from these figures that the Avrami model provided a much better prediction of the experimental data than did the Tobin model.

\subsubsection{Ozawa analysis}

By simply replacing $t$ in Eq. (1) with $T / \phi$, Ozawa [2] was able to extend the Avrami model to describe the kinetics of nonisothermal crystallization observed using a DSC. In this case, the raw data is the relative crystallinity as a function of temperature $\theta(T)$, such as those shown in Fig. 3. As mentioned previously, data analysis can be accomplished using a double logarithmic plot of $\ln [-\ln (1-\theta(T))]$ versus $\ln (\phi)$ for a fixed temperature, in which $k_{\mathrm{O}}$ is taken as the antilogarithmic value of the $y$-intercept and $n_{\mathrm{O}}$ is simply the negative value of the slope. Fig. 6 shows such a plot for PTT, while Table 4 summarizes values of the Ozawa kinetic parameters (i.e. $k_{\mathrm{O}}$ and $n_{\mathrm{O}}$ ), including the $r^{2}$ parameter, for all of the polyesters studied.

Based on the plots shown in Fig. 6 and the correlation coefficients $r^{2}$ listed in Table 4, the Ozawa 
model [2] was found to provide a satisfactory description of the nonisothermal crystallization kinetics of these polyesters in the temperature range studied. In all cases, the Ozawa exponent $n_{\mathrm{O}}$ was found to range from ca. 1.7 to 4.5 . More specifically, it ranged from ca. 1.7 to 2.1 for PET within the temperature range of $170-190^{\circ} \mathrm{C}$, from ca. 2.7 to 4.5 for PTT within the temperature range of $160-180^{\circ} \mathrm{C}$, and from ca. 1.9 to 2.7 for PBT within the temperature range of $180-198^{\circ} \mathrm{C}$, respectively. In the case of PTT, the values of $n_{\mathrm{O}}$ obtained were greater than those previously reported [29]. Values of $n_{\mathrm{O}}$ in the range of 1.7-3.1 were obtained for PTT having a number-average molecular weight of $23,000 \mathrm{Da}$
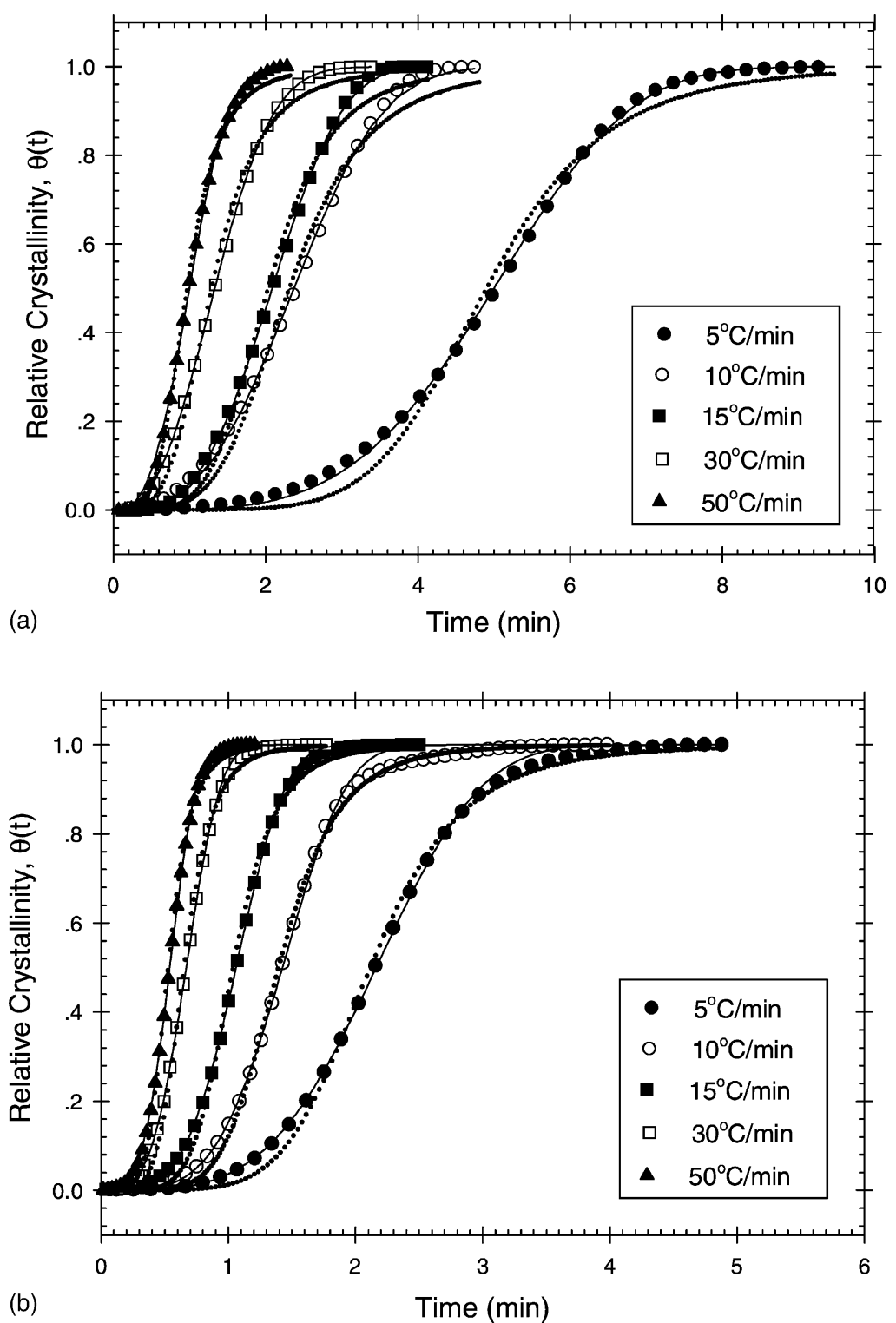

Fig. 5. Relative crystallization as a function of time for (a) PET, (b) PTT, and (c) PBT at five different cooling rates. Model prediction based on Avrami and Tobin equations are shown as solid and dotted lines, respectively. 


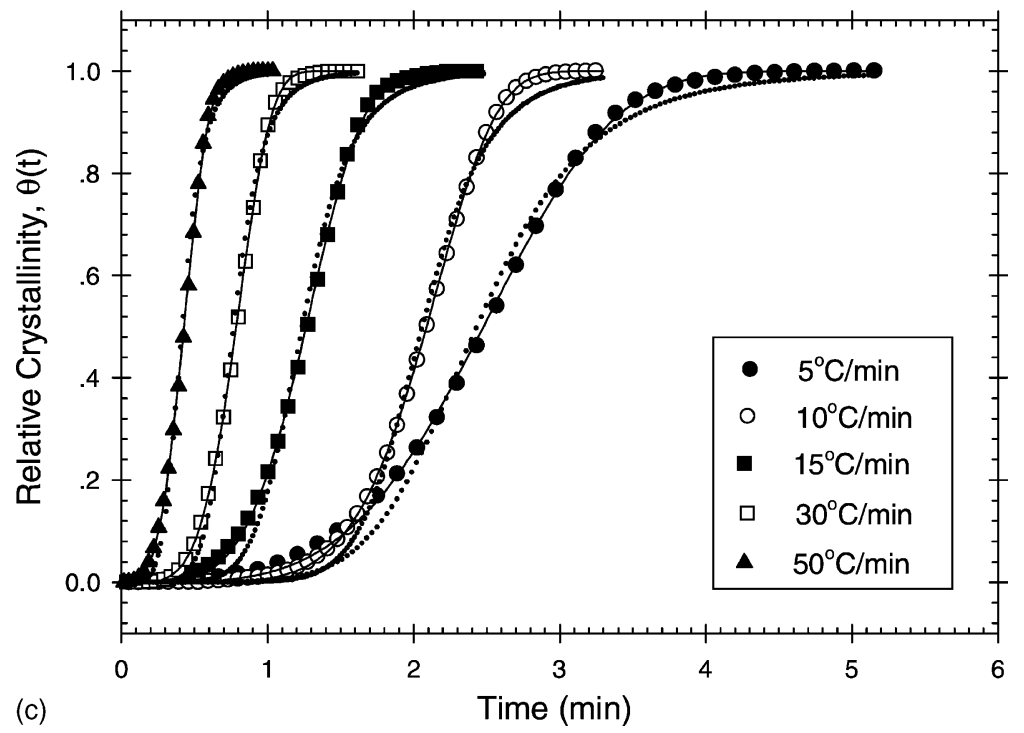

Fig. 5. (Continued).

within the temperature range of $160-192^{\circ} \mathrm{C}$. With regards to the Ozawa crytallization rate function $k_{\mathrm{O}}$, values similar to those for the Avrami and the Tobin crystallization rate constants (i.e. $K_{\mathrm{A}}$ and $K_{\mathrm{T}}$ ) were obtained.

\subsection{Ziabicki's kinetic crystallizability analysis}

Table 5 summarizes the values of $T_{\max }, \dot{\theta}_{\max , \phi}$, and $D_{\phi}$ for all of the three polyesters studied. The values of these parameters were used to calculate the

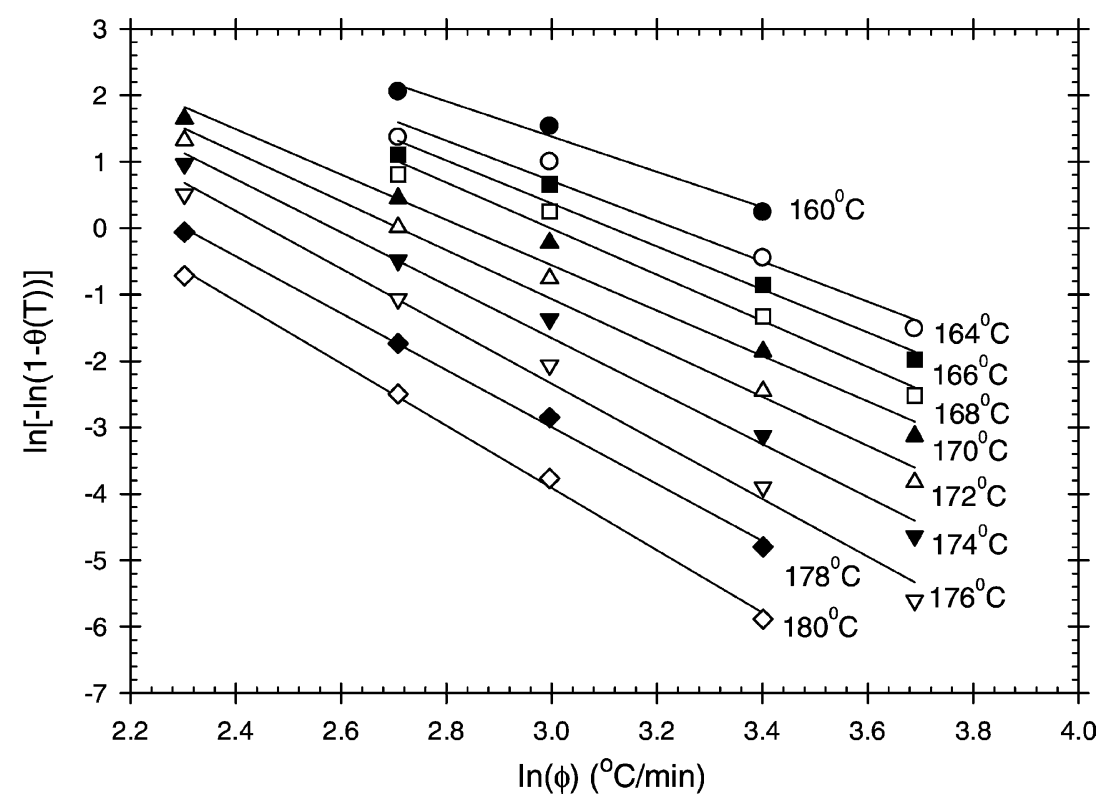

Fig. 6. Typical Ozawa analysis based on nonisothermal crystallization data for PTT. 
Table 4

Nonisothermal crystallization kinetic parameters for PET, PTT, and PBT based on Ozawa analysis

\begin{tabular}{|c|c|c|c|c|c|c|c|c|c|c|c|}
\hline \multicolumn{4}{|l|}{ PET } & \multicolumn{4}{|l|}{ PTT } & \multicolumn{4}{|l|}{ PBT } \\
\hline $\begin{array}{l}\text { Temperature } \\
\left({ }^{\circ} \mathrm{C}\right)\end{array}$ & $n_{\mathrm{O}}$ & $\begin{array}{l}k_{\mathrm{O}} \\
\left({ }^{\circ} \mathrm{C} \min ^{-1}\right)^{n}\end{array}$ & $r^{2}$ & $\begin{array}{l}\text { Temperature } \\
\left({ }^{\circ} \mathrm{C}\right)\end{array}$ & $n_{\mathrm{O}}$ & $\begin{array}{l}k_{\mathrm{O}} \\
\left({ }^{\circ} \mathrm{C} \min ^{-1}\right)^{n}\end{array}$ & $r^{2}$ & $\begin{array}{l}\text { Temperature } \\
\left({ }^{\circ} \mathrm{C}\right)\end{array}$ & $n_{\mathrm{O}}$ & $\begin{array}{l}k_{\mathrm{O}} \\
\left({ }^{\circ} \mathrm{C} \min ^{-1}\right)^{n}\end{array}$ & $r^{2}$ \\
\hline 170 & 2.09 & $5.32 \times 10^{2}$ & 0.9762 & 160 & 2.65 & $1.14 \times 10^{4}$ & 0.9779 & 180 & 2.06 & $1.11 \times 10^{3}$ & 0.9852 \\
\hline 172 & 2.04 & $3.82 \times 10^{2}$ & 0.9779 & 164 & 3.03 & $1.80 \times 10^{4}$ & 0.9724 & 182 & 2.20 & $1.24 \times 10^{3}$ & 0.9949 \\
\hline 174 & 2.00 & $2.87 \times 10^{2}$ & 0.9792 & 166 & 3.24 & $2.41 \times 10^{4}$ & 0.9769 & 184 & 2.24 & $9.36 \times 10^{2}$ & 0.9935 \\
\hline 176 & 1.97 & $2.19 \times 10^{2}$ & 0.9806 & 168 & 3.47 & $3.25 \times 10^{4}$ & 0.9827 & 186 & 2.03 & $2.96 \times 10^{2}$ & 0.9736 \\
\hline 178 & 1.73 & $1.04 \times 10^{2}$ & 0.9863 & 170 & 3.83 & $5.05 \times 10^{4}$ & 0.9729 & 188 & 2.14 & $2.51 \times 10^{2}$ & 0.9730 \\
\hline 180 & 1.74 & $8.53 \times 10^{1}$ & 0.9899 & 172 & 4.13 & $7.46 \times 10^{4}$ & 0.9737 & 190 & 1.94 & $1.04 \times 10^{2}$ & 0.9898 \\
\hline 182 & 1.78 & $7.69 \times 10^{1}$ & 0.9925 & 174 & 4.54 & $1.34 \times 10^{5}$ & 0.9700 & 192 & 2.12 & $9.64 \times 10^{1}$ & 0.9959 \\
\hline 184 & 1.84 & $7.20 \times 10^{1}$ & 0.9945 & 176 & 4.33 & $4.26 \times 10^{4}$ & 0.9908 & 194 & 2.28 & $7.94 \times 10^{1}$ & 0.9987 \\
\hline 186 & 1.91 & $6.92 \times 10^{1}$ & 0.9959 & 178 & 3.72 & $3.57 \times 10^{3}$ & 0.9872 & 196 & 2.46 & $6.24 \times 10^{1}$ & 0.9979 \\
\hline 188 & 1.99 & $6.69 \times 10^{1}$ & 0.9963 & 180 & 4.03 & $3.60 \times 10^{3}$ & 0.9852 & 198 & 2.69 & $5.08 \times 10^{1}$ & 0.9909 \\
\hline 190 & 2.09 & $6.45 \times 10^{1}$ & 0.9957 & - & - & - & - & - & - & - & - \\
\hline
\end{tabular}

Ziabicki's kinetic crystallizability $G$, also summarized in Table 5. For a given polyester, the temperature at the maximum crystallization rate $T_{\max }$ was found to decrease with increasing cooling rate, whereas both of the maximum crystallization rate $\dot{\theta}_{\max , \phi}$ and the half-width of the derivative relative crystallinity function of temperature $D_{\phi}$ were all found to increase with increasing cooling rate. Based on these values, the resulting cooling-rate-dependent kinetic crystallizability $G_{\phi}$ (results not shown) was an increasing function of the cooling rate. After normalization of the cooling rate, the values of the kinetic crystallizability $G$ (for unit cooling rate) appeared to be qualitatively similar (cf. Table 5).

The practical meaning of kinetic crystallizability $G$ is the ability of a semicrystalline polymer to crystallize when it is cooled from the melt to the glassy state at a unit cooling rate; hence, the higher the $G$ values, the more readily the polymer crystallizes. From Table 5, it is obvious that PBT exhibited the highest average $G$ value (i.e. ca. 1.7), followed by PTT (i.e. ca. 1.5) and PET (i.e. ca. 1.1), respectively. The result suggests that the crystallization propensity of these polyesters is in the following order: PBT $>$ PTT $>$ PET. Interestingly, the $G$ value of 1.1 for PET appears to be identical to the value reported previously [17].

\subsection{Effective energy barrier for nonisothermal crystallization process}

The application of the differential isoconversional method of Friedman to the experimental data for nonisothermal crystallization from the melt state of PET, PTT, and PBT resulted in the estimation of the

Table 5

Ziabicki's kinetic crystallizability parameters for PET, PTT, and PBT calculated from the data for nonisothermal crystallization

\begin{tabular}{|c|c|c|c|c|c|c|c|c|c|c|c|c|}
\hline \multirow{2}{*}{$\begin{array}{l}\phi \\
\left({ }^{\circ} \mathrm{C} \min ^{-1}\right)\end{array}$} & \multicolumn{4}{|l|}{ PET } & \multicolumn{4}{|l|}{ PTT } & \multicolumn{4}{|l|}{ PBT } \\
\hline & $\begin{array}{l}T_{\max , \phi} \\
\left({ }^{\circ} \mathrm{C}\right) \\
\end{array}$ & $\dot{\theta}_{\max , \phi}\left(\mathrm{s}^{-1}\right)$ & $\begin{array}{l}D_{\phi} \\
\left({ }^{\circ} \mathrm{C}\right) \\
\end{array}$ & $G$ & $\begin{array}{l}T_{\max , \phi} \\
\left({ }^{\circ} \mathrm{C}\right)\end{array}$ & $\dot{\theta}_{\max , \phi}\left(\mathrm{s}^{-1}\right)$ & $\begin{array}{l}D_{\phi} \\
\left({ }^{\circ} \mathrm{C}\right) \\
\end{array}$ & $G$ & $\begin{array}{l}T_{\max , \phi} \\
\left({ }^{\circ} \mathrm{C}\right)\end{array}$ & $\dot{\theta}_{\max , \phi}\left(\mathrm{s}^{-1}\right)$ & $\begin{array}{l}D_{\phi} \\
\left({ }^{\circ} \mathrm{C}\right)\end{array}$ & $G$ \\
\hline 5 & 196.23 & $4.97 \times 10^{-3}$ & 19.44 & 1.23 & 185.82 & $1.05 \times 10^{-2}$ & 9.84 & 1.31 & 196.90 & $9.79 \times 10^{-3}$ & 13.10 & 1.64 \\
\hline 10 & 185.97 & $7.06 \times 10^{-3}$ & 20.75 & 0.93 & 178.63 & $1.91 \times 10^{-2}$ & 11.52 & 1.41 & 192.13 & $1.71 \times 10^{-2}$ & 17.44 & 1.91 \\
\hline 15 & 179.45 & $8.93 \times 10^{-3}$ & 21.93 & 0.83 & 173.45 & $2.23 \times 10^{-2}$ & 19.66 & 1.86 & 187.20 & $2.11 \times 10^{-2}$ & 21.69 & 1.95 \\
\hline 20 & 172.27 & $8.84 \times 10^{-3}$ & 43.87 & 1.24 & 170.27 & $2.99 \times 10^{-2}$ & 18.37 & 1.75 & 186.93 & $2.56 \times 10^{-2}$ & 17.80 & 1.45 \\
\hline 30 & 164.40 & $1.17 \times 10^{-2}$ & 45.06 & 1.12 & 163.90 & $3.26 \times 10^{-2}$ & 20.36 & 1.41 & 181.40 & $3.55 \times 10^{-2}$ & 20.65 & 1.56 \\
\hline 40 & 163.87 & $1.56 \times 10^{-2}$ & 46.89 & 1.17 & 158.53 & $3.67 \times 10^{-2}$ & 24.99 & 1.46 & 177.20 & $4.03 \times 10^{-2}$ & 24.00 & 1.54 \\
\hline 50 & 163.17 & $2.03 \times 10^{-2}$ & 48.39 & 1.26 & 152.33 & $3.63 \times 10^{-2}$ & 28.46 & 1.32 & 174.00 & $5.03 \times 10^{-2}$ & 25.67 & 1.65 \\
\hline Average & & & & 1.11 & & & & 1.50 & & & & 1.67 \\
\hline
\end{tabular}


Table 6

Effective energy barrier $\Delta E$ describing the overall crystallization process of PET, PTT, and PBT

\begin{tabular}{|c|c|c|c|c|c|c|c|c|c|c|}
\hline \multirow[t]{2}{*}{ Polymer } & \multicolumn{10}{|c|}{$\Delta E\left(\mathrm{~kJ} \mathrm{~mol}^{-1}\right)$} \\
\hline & $\theta=0.1$ & $r^{2}$ & $\theta=0.3$ & $r^{2}$ & $\theta=0.5$ & $r^{2}$ & $\theta=0.7$ & $r^{2}$ & $\theta=0.9$ & $r^{2}$ \\
\hline PET & -113.9 & 0.97 & -72.5 & 0.94 & -49.8 & 0.91 & -28.2 & 0.72 & -16.8 & 0.40 \\
\hline PTT & -82.6 & 0.93 & -64.0 & 0.86 & -52.9 & 0.80 & -46.0 & 0.76 & -52.5 & 0.82 \\
\hline PBT & -181.9 & 0.96 & -147.7 & 0.95 & -126.6 & 0.98 & -121.0 & 0.98 & -104.9 & 0.95 \\
\hline
\end{tabular}

effective energy barrier for nonisothermal crystallization $\Delta E$ of these polymers. According to Table 6, the $\Delta E$ values for both PET and PBT were found to increase monotonically with the relative extent of melt conversion or the relative degree of crystallinity (i.e. from ca. -133.9 to $-16.8 \mathrm{~kJ} \mathrm{~mol}^{-1}$ for PET and from ca. -181.9 to $-104.9 \mathrm{~kJ} \mathrm{~mol}^{-1}$ for PBT, respectively). For PTT however, the $\Delta E$ value was found to increase with the relative degree of crystallinity up to a $\theta$ of ca. 0.7 , where the $\Delta E$ value attained a maximum value and then decreased again as the relative degree of crystallinity further increased. Specifically, the $\Delta E$ value for PTT was found to lie within the range of ca. -82.6 to $-46.0 \mathrm{~kJ} \mathrm{~mol}^{-1}$. The variation of the $\Delta E$ value with the relative degree of crystallinity has been attributed to the temperature dependence of the energy barrier for nucleation, which decreases with increasing extent of melt conversion or decreasing temperature (in the case of nonisothermal crystallization from the melt state) [30].

For PET, the effective energy barrier for nonisothermal crystallization $\Delta E$ which was evaluated by the integral isoconversional method of Vyazovkin [25,26] exhibited an increase in its value with increasing extent of melt conversion from ca. -240 to $-125 \mathrm{~kJ} \mathrm{~mol}^{-1}$ (reported for the similar relative crystallinity range of 0.1-0.9 which was used to obtain the $\Delta E$ value for PET in this work) [30]. Obviously, the $\Delta E$ values reported by Vyazovkin and Sbirrazzuoli [30] was much lower than the values obtained in this work. Possible discrepancies of the values reported may be attributed to the difference in the average molecular weights of the PET resins used (i.e. the weight-average molecular weights of PET used in [30] and this work were 18,000 and $78,100 \mathrm{Da}$, respectively), to the difference in the type and concentration of heterogeneous nuclei present in the resins, and to the noise that arose from the differentiation of the experimental data in order to obtain the instantaneous crystallization rate as a func- tion of time which must be used to obtain the $\Delta E$ value in the Friedman method [26].

\section{Conclusions}

The nonisothermal crystallization exotherms for three polyesters, PET, PTT, and PBT, showed that the temperature at $1 \%$ relative crystallinity, the peak temperature, and the temperature at $99 \%$ relative crystallinity all shifted towards lower temperatures with increasing cooling rate. The half-time of crystallization was found to decrease with increasing cooling rate, suggesting that these polymers took a shorter time to crystallize when the cooling rate increased. The Avrami model was found to provide a much better fit to the experimental data for crystallization of these polyesters than did the Tobin model.

For PTT samples, the Avrami exponent $n_{\mathrm{A}}$ was found to range from 3.2 to 4.1 , while the Tobin exponent $n_{\mathrm{T}}$ was found to range from 5.7 to 6.4. In addition, the Ozawa model was found to provide a fair description to the experimental data for crystallization of these polyesters, with the Ozawa exponent $n_{\mathrm{O}}$ found to range from 2.7 to 4.5 , which is quite comparable to the Avrami exponent $n_{\mathrm{A}}$ obtained. All of the bulk crystallization rate parameters (i.e. $K_{\mathrm{A}}$ and $K_{\mathrm{T}}$ ) were found to increase with the cooling rate, suggesting that these polyesters crystallized faster at greater cooling rates.

The ability of PET, PTT, and PBT to crystallize from the melt under a unit cooling rate can be determined by comparing the values of the Ziabicki's kinetic crystallizability $G$, which were found to be ca. 1.1, 1.5, and 1.7 for PET, PTT, and PBT, respectively. According to these values, the propensity for these polyesters to crystallize is in the following order: PBT $>$ PTT $>$ PET. Lastly, the effective energy barrier governing the nonisothermal melt-crystallization of these polyesters, 
based on the values provided by the differential isoconversional method of Friedman, was found to increase with increasing relative degree of crystallinity.

\section{Acknowledgements}

The authors wish to thank Dr. Hoe H. Chuah and his co-workers of Shell Chemical Company (USA) Ltd. for supply of PTT and for their kind assistance with molecular weight measurements on all of the polyester resins received, Dr. Gi-Dae Choi and Soo-Min Lee of LG Chem (Korea) Ltd. for supply of PBT, and Indo PET (Thailand) Ltd. for supply of PET. PS acknowledges a grant provided by Chulalongkorn University through the Development Grants for New Faculty/ Researchers. Partial support from the Petroleum and Petrochemical Technology Consortium and the Petroleum and Petrochemical College is also greatly acknowledged.

\section{References}

[1] Whinfield JR, Dickson JT, Br. Patent 578,079 (14 June 1946).

[2] T. Ozawa, Polymer 12 (1971) 150.

[3] F. Rybnikar, C. Coll, Chem. Commun. 25 (1960) 1529.

[4] F. Rybnikar, C. Coll, Chem. Commun. 25 (1960) 1540.

[5] A. Keller, G.R. Lester, L.B. Morgan, Philos. Trans. R. Soc. London, Ser. A 247 (1954) 1.
[6] F.D. Hartley, F.W. Lord, L.B. Morgan, Philos. Trans. R. Soc. London, Ser. A 247 (1954) 24.

[7] M. Avrami, J. Chem. Phys. 7 (1939) 1103.

[8] M. Avrami, J. Chem. Phys. 8 (1940) 212.

[9] M. Avrami, J. Chem. Phys. 9 (1941) 177.

[10] B. Wunderlich, Macromolecular Physics, vol. 2, Academic Press, New York, 1976, p. 147.

[11] M.C. Tobin, J. Polym. Sci.: Polym. Phys. 12 (1974) 399.

[12] M.C. Tobin, J. Polym. Sci.: Polym. Phys 14 (1976) 2253.

[13] M.C. Tobin, J. Polym. Sci.: Polym. Phys. 15 (1977) 2269.

[14] U.R. Evans, Trans. Faraday Soc. 41 (1945) 365.

[15] A. Ziabicki, Appl. Polym. Symp. 6 (1967) 1.

[16] A. Ziabicki, Polymer 12 (1967) 405.

[17] A. Ziabicki, Fundamentals of Fiber Spinning, Wiley, New York, 1976, pp. 112-114.

[18] A. Jeziorny, Polymer 19 (1978) 1142.

[19] J.A. Augis, J.E. Bennett, J. Therm. Anal. 13 (1978) 283.

[20] H.E. Kissinger, J. Res. Natl. Bur. Stand. 57 (1956) 217.

[21] R.L. Takhor, Advances in Nucleation and Crystallization of Glasses, American Ceramics Society, Columbus, 1971, pp. 166-172.

[22] S. Vyazovkin, Macromol. Rapid Commun. 23 (2002) 771.

[23] P. Supaphol, J. Appl. Polym. Sci. 78 (2000) 338.

[24] H. Friedman, J. Polym. Sci. C 6 (1964-1965) 183.

[25] S. Vyazovkin, J. Comput. Chem. 18 (1997) 393.

[26] S. Vyazovkin, J. Comput. Chem. 22 (2001) 178.

[27] N. Dangseeyun, P. Srimoaon, P. Supaphol, M. Nithitanakul, Thermochim. Acta, submitted for publication.

[28] A. Duillard, P.H. Dumazed, B. Chabert, J. Guillet, Polymer 34 (1993) 1702.

[29] X.S. Wang, D. Yan, G.H. Tian, X.G. Li, Polym. Eng. Sci. 41 (2001) 1655.

[30] S. Vyazovkin, N. Sbirrazzuoli, Macromol. Rapid Commun. 23 (2002) 766. 